\title{
Optimization of Material Removal Rate and Surface Roughness of AISI 316L un- der Dry Turning Process using Genetic Algorithm
}

\author{
Sigit Yoewono Martowibowo (ORCID: 0000-0003-2720-0558)ㄹ, Bivynka Kemala Damanik (ORCID: 0000-0003- \\ 3844-1437) $)^{2}$ \\ ${ }^{1}$ Faculty of Manufacturing Technology, Universitas Jenderal Achmad Yani, \\ Jalan Terusan Jenderal Gatot Subroto, Bandung 40284, Indonesia. E-mail: sigit.yoewono@lecture.unjani.ac.id; si- \\ git@ftmd.itb.ac.id. \\ ${ }^{2}$ Alliance Manchester Business School, The University of Manchester, Booth Street West, Manchester, M15 6PB, \\ United Kingdom. E-mail: bivynkadamanik@gmail.com.
}

The turning process is one of the most common machining operations in various manufacturing industries. It is conducted by eroding the rotating workpiece using a tool that moves in a linear motion. This study examined the genetic algorithm (GA) as the optimization method for the dry turning process of AISI 316L. GA is a meta-heuristic method that imitates the principle of natural selection, in which the most suitable individuals are selected for reproduction to produce the next generation of offspring. The optimization process was started by executing the selected experimental design based on the process parameters and their levels. The tool nose radius, cutting speed, feed rate, and depth of cut were selected as the process parameters in this study. The outcome of this step was a fitness function that explained the relationship between the process parameters and the material removal rate (MRR) or the surface roughness (SR). GA used the fitness function to produce the optimal process parameters with the highest MRR and the lowest SR in a separate optimization process. The optimization methodology developed in this study can be utilized to predict the optimum value of the MRR and SR for the dry turning process and with less than a $7 \%$ deviation from the actual value.

Keywords: Dry Turning Process, Genetic Algorithm, Material Removal Rate, Optimization, Surface Roughness

\section{Introduction}

Material removal rate and surface roughness play an important role in many fields and are very important factors in evaluating machining accuracy $[1,2]$. The turning process is one of the important and widely used machining operations in the manufacturing industry. In the turning process, cutting conditions (such as cutting speed, feed rate, depth of cut, tool conditions, and workpiece material) will affect processing efficiency and performance characteristics. Need to choose the most suitable machining settings to improve cutting efficiency, low-cost processes, and highquality products.

Cleaner production has become a goal within the present manufacturing industries. Key methods of reducing the environmental pollution in the process of manufacturing involve the reduction of pollution generated by coolants. Cleaner production is a concept that can improve environmental performance [3]. Their experiments were carried out in dry and cooling/lubricating conditions, and involved the measurements of surface roughness, cutting force, tool life, cutting energy, and tool-chip friction coefficient. They focused on dry cutting effects in turning duplex stainless steel using the coated carbide tools. Chen et al. conducted an experiment to study the effect of cemented carbide tools on the surface roughness of stainless steel under dry turning conditions. From their conclusions, it can be seen that as the tool wear increases, the surface roughness of the workpiece increases significantly, so the quality of the surface of the workpiece decreases significantly [4]. Their research can provide a reference for dry cutting with cemented carbide tools.

In various engineering fields, the application of stainless steel materials has greatly increased. Austenitic stainless steel (ASS) grade has high chromium content and low molybdenum content and is an excellent engineering material. AISI $316 \mathrm{~L}$ is a chromium-nickelmolybdenum ASS and is developed to provide corrosion resistance in moderately corrosive environments that can be applied in biomedical devices and implants in the human body $[5,6]$. Asiltürk and Akkus conducted dry turning experiments on AISI 4140 hardened steel using coated carbide tools. Their conclusion shows that the feed rate has a greater influence on the surface roughness [7].

The development of the manufacturing process significantly creates the need for an optimization process, to obtain more efficient results, both cost and time efficiency. Mathematically, optimization is a way 
of getting extreme values both maximum and minimum of a particular function with its limiting factors [8]. Harhout et al. [9] made a study using a combination of Polynomial Regression, ANOVA dan Response Surface Methodology to investigate the effect of turning process parameters on AISI 1050 and to optimize its surface roughness and material removal rate.

The ability of the Genetic Algorithm (GA) as a random search method to obtain optimal global values makes this method often used. Based on studies conducted by various researchers, this method can be used in various manufacturing processes with satisfactory results [10-12].

The purpose of this study was to obtain the value of the dry turning process parameters to achieve the optimal material removal rate (MRR) and surface roughness (SR) using the GA optimization method. The optimization process is conducted using data obtained from a limited number of experiments. The data is processed according to the GA optimization method so that the results are considered optimal. These results are verified and validated by conducting experiments using the optimization parameter results.

\section{Experimental Investigation}

The experimental setup used a lathe machine LA530, as shown in Fig. 1. This machine has 12 levels for rotating speed and 16 levels for the feeding rate. The workpiece material used is a cylindrical bar of AISI 316L steel with a hardness of $195 \mathrm{BHN}$, a length of $100 \mathrm{~mm}$, and a diameter of $63 \mathrm{~mm}$. The cutting tool inserts used for the experimental work are tungsten carbides with specification VBMT-160404 and VCMT-160408. The surface roughness of the turned workpiece was measured with a Mitutoyo surface roughness tester (SJ-410), and its cut-off value was 0.8 mm. (Fig. 2).

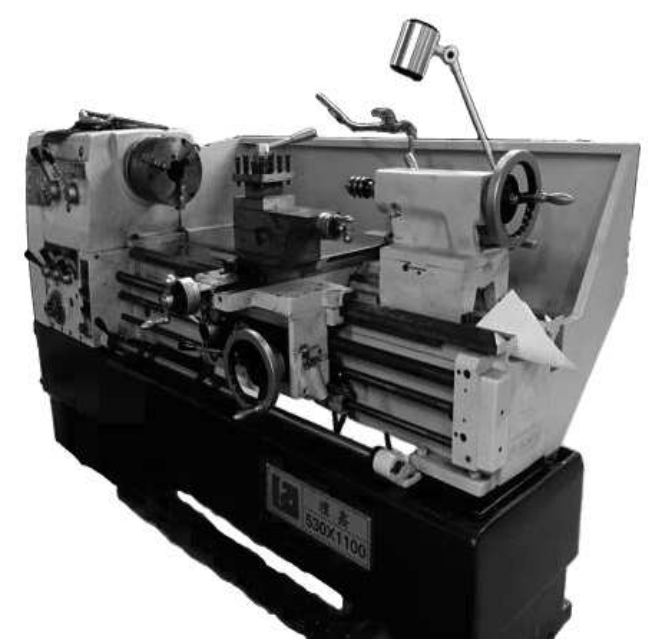

Fig. 1 Lathe Machine using for the Experiments

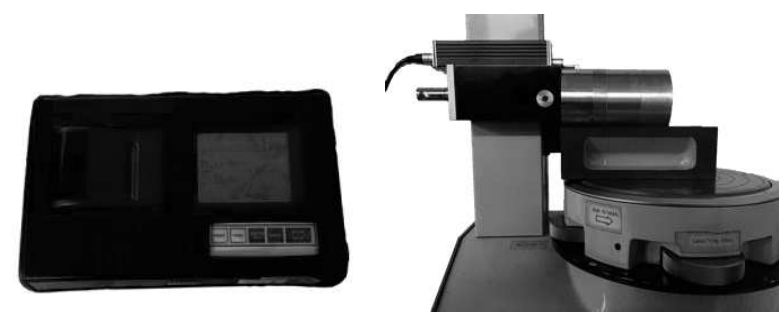

Fig. 2 Portable Surface Roughness Tester

\subsection{Methodology}

The methodology is a representation of the sequence of the activities in the research work. The steps involved in data collection, model development, and optimization in this study are summarized as follows: 1) Identify process parameters and responses; 2) Find out the limits and levels of process parameters; 3 ) Construction of experimental design; 4) Experimental work and data collection; 5) Establish a mathematical model; 6) Optimize process parameters; 7) Validation of experiment.

The cutting speed, feed rate, and depth of cut have a direct influence on MRR. In addition, the cutting speed, feed rate, and tool nose radius influence on SR. Therefore, in this study, it is critical to investigate the effect of cutting speed, feed rate, depth of cut, and tool nose radius on MRR and SR.

The work begins by determining the number of independent process parameters and their levels. The process parameters are tool nose radius, cutting speed, feed rate, and depth of cut, while the levels are determined based on the range contained in the reference source. In this study, the reference used is the Mitsubishi Technical Data for workpiece material and tool material used [13]. Tab. 1 shows the process parameters and their corresponding levels.

Tab. 1 Process Parameters and Their Levels

\begin{tabular}{|c|c|c|c|c|}
\hline $\begin{array}{c}\text { Sym- } \\
\text { bol }\end{array}$ & Process parameters & \multicolumn{3}{|c|}{ Levels } \\
\cline { 3 - 5 }$r_{\varepsilon}$ & $\begin{array}{c}\text { Tool nose radius } \\
(\mathrm{mm})\end{array}$ & 0.4 & 0.8 & - \\
\hline$v_{c}$ & $\begin{array}{c}\text { Cutting speed } \\
\left(\mathrm{m}_{\mathrm{min}^{-1}}\right)\end{array}$ & 95 & 127 & 185 \\
\hline$f$ & $\begin{array}{c}\text { Feed rate }\left(\mathrm{mm} \cdot \mathrm{rev}^{-}\right. \\
\text {) }\end{array}$ & 0.053 & 0.11 & 0.21 \\
\hline$d$ & Depth of cut $(\mathrm{mm})$ & 0.3 & 0.6 & 0.9 \\
\hline
\end{tabular}

\subsection{Development of mathematical models}

The model generated by this method is influenced by various parameters, while the objective is to optimize the model. The response is expressed as a function of process parameters as variables and is called a multiple regression model. In general, a multiple regression second-order cross-product model with $\mathrm{k}$ independent variables is given by Eq. 1 [14]: 


$$
\begin{gathered}
y_{i}=\beta_{0}+\sum_{j=1}^{k} \beta_{j} x_{i j}+\sum_{j=1}^{k} \beta_{j j} x_{i j}^{2}+\sum_{j<i}^{k} \beta_{i j} x_{i} x_{j} \\
i=1,2,3 \ldots, n ; j=1,2,3 \ldots, k
\end{gathered}
$$

Where: $\beta_{0}$ is a constant term, $\beta_{j}$ is the coefficient of the linear terms, $\beta_{j j}$ is the coefficient of the quadratic terms, $\beta_{i j}$ is the coefficient of the cross product term, and $x_{i}, x_{j}$ are variables.

\subsection{Genetic algorithms}

Genetic algorithm (GA) is a computerized search and optimization algorithm based on the biological evolution process and was first introduced by Holland in the year of 1970s [15]. Due to its simplicity, ease of operation, minimum requirements, and overall nature, GA has been successfully used for various problems [16]. GA simulates the characteristics of a biological system such as self-repair and reproduction. The evolutionary process is random but guided by a selection mechanism based on the suitability of a single structure. GA starts with a series of possible solutions to problems and then develops into better solutions. A group of individuals represents a population, and each population will generate other populations until a certain number of generations are generated, or the population's satisfactory adaptation level is reached. In general, the GA optimization process follows the following process: determining the initial population, evaluation, selection, crossover, and mutation. The first generation is obtained by randomly generating a population with predetermined chromosomes. To obtain the required solution and the number of chromosomes in the population, the process needs to meet a set of requirements $[10,17]$. In each chromosome, there are several genes. Through the analogous biological evolution, each gene in the chromosome indicates a specific process parameter. For instance, gene 1 represents the tool nose radius, gene 2 represents the cutting speed, gene 3 represents the feed rate, and gene 4 represents the depth of cut. If the number of chromosomes used is too small, the individuals available for the crossover and mutation process will be very limited, making the whole process futile. On the contrary, too many chromosomes will also slow down the process of GA. It is recommended that the number of chromosomes is higher than the number of genes in a single chromosome. However, it is also recommended not to consider the nature of the problem, because too many genes are not recommended [10].

\subsection{Design of experiments}

The minimum number of experiments that can represent the overall data is the $\mathrm{L}_{18}$ orthogonal array. The process of determining the combination of each process parameter and its level is carried out with the help of Minitab software. The results of the combination of each independent variable from Minitab can be seen in Tab. 2 in the form of the design of experiments. The cutting process model is formulated in terms of cutting conditions namely tool nose radius, cutting speed, feed rate, and depth of cut.

Tab. 2 Design of Experiments

\begin{tabular}{|c|c|c|c|c|}
\hline \multirow{2}{*}{ No. } & $\begin{array}{c}\text { Tool nose radius } r_{\varepsilon} \\
(\mathrm{mm})\end{array}$ & $\begin{array}{c}\text { Cutting speed } v_{c} \\
\left(\mathrm{~m}^{\mathrm{min}}{ }^{-1}\right)\end{array}$ & Feed rate $f\left(\mathrm{~mm}_{\text {.rev }}{ }^{-1}\right)$ & $\begin{array}{c}\text { Depth of cut } d \\
(\mathrm{~mm})\end{array}$ \\
\cline { 2 - 5 } & $x_{1}$ & $x_{2}$ & $x_{3}$ & $x_{4}$ \\
\hline 1 & 0.4 & 95 & 0.053 & 0.3 \\
\hline 2 & 0.4 & 95 & 0.11 & 0.9 \\
\hline 3 & 0.4 & 95 & 0.21 & 0.3 \\
\hline 4 & 0.4 & 127 & 0.053 & 0.6 \\
\hline 5 & 0.4 & 127 & 0.11 & 0.9 \\
\hline 6 & 0.4 & 127 & 0.21 & 0.6 \\
\hline 7 & 0.4 & 185 & 0.053 & 0.9 \\
\hline 8 & 0.4 & 185 & 0.11 & 0.3 \\
\hline 9 & 0.4 & 185 & 0.21 & 0.3 \\
\hline 10 & 0.8 & 95 & 0.053 & 0.6 \\
\hline 11 & 0.8 & 95 & 0.11 & 0.6 \\
\hline 12 & 0.8 & 95 & 0.21 & 0.9 \\
\hline 13 & 0.8 & 127 & 0.053 & 0.3 \\
\hline 14 & 0.8 & 127 & 0.11 & 0.9 \\
\hline 15 & 0.8 & 127 & 0.21 & 0.3 \\
\hline 16 & 0.8 & 185 & 0.053 & 0.6 \\
\hline 17 & 0.8 & 185 & 0.11 & \\
\hline 18 & 0.8 & 185 & 0.21 & \\
\hline
\end{tabular}




\section{Results and Discussion}

\subsection{Experimental and modeling}

The response produced by this experiment is the MRR and SR. The MRR value is obtained using the following equation:

$$
M R R=\frac{V}{t_{c}}
$$

The volume of the cut material ( $V$ ) is obtained by subtracting the material initial weight with the final weight after machining and divided by the density of

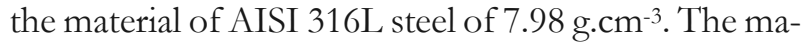
chining time of $t_{c}$ is measured by using a stopwatch. SR values are obtained using a surface roughness measuring device.

The developed models for predicting MRR and SR are represented by Eqs. 3 and 4:

$$
\begin{aligned}
y_{1}= & 4.05+0.334 x_{1}+1.04 x_{2}+2.12 x_{3}+1.98 x_{4}+0.0892 x_{1} x_{2}+0.686 x_{1} x_{3}-0.383 x_{1} x_{4}+ \\
& 0.832 x_{2} x_{3}+0.345 x_{2} x_{4}+0.505 x_{3} x_{4} \\
y_{2}= & 1.88-0.0501 x_{1}-0.0794 x_{2}+0.6 x_{3}+0.162 x_{4}-0.213 x_{1} x_{2}-0.188 x_{1} x_{3}+0.156 x_{1} x_{4}+ \\
& 0.0616 x_{2} x_{3}-0.139 x_{2} x_{4}-0.116 x_{3} x_{4}
\end{aligned}
$$

Tab. 3MRR and SR Results from Experiment and Modeling

\begin{tabular}{|c|c|c|c|c|}
\hline \multirow{2}{*}{ No. } & \multicolumn{2}{|c|}{ MRR } & \multicolumn{2}{c|}{ SR } \\
\cline { 2 - 5 } & $y_{1 / \text { (exp) }}\left(\mathrm{cm}^{3} \cdot \mathrm{min}^{-1}\right)$ & $y_{1(\text { model })}\left(\mathrm{cm}^{3} \cdot \mathrm{min}^{-1}\right)$ & $\begin{array}{c}y_{2(\exp )} \\
(\mu \mathrm{m})\end{array}$ & $\begin{array}{c}y_{2(\text { (model })} \\
(\mu \mathrm{m})\end{array}$ \\
\hline 1 & 0.83 & 0.39 & 0.75 & 0.69 \\
\hline 2 & 2.75 & 2.60 & 1.54 & 1.64 \\
\hline 3 & 6.89 & 6.59 & 2.91 & 2.73 \\
\hline 4 & 0.47 & 0.10 & 1.01 & 0.88 \\
\hline 5 & 1.73 & 3.24 & 1.32 & 1.74 \\
\hline 6 & 8.37 & 8.62 & 2.84 & 1.76 \\
\hline 7 & 1.74 & 2.26 & 1.39 & 1.74 \\
\hline 8 & 8.51 & 7.62 & 1.63 & 3.58 \\
\hline 9 & 4.22 & 4.10 & 3.55 & 2.46 \\
\hline 10 & 1.84 & 1.99 & 2.72 & 1.48 \\
\hline 11 & 0.70 & 1.43 & 1.54 & 2.59 \\
\hline 12 & 5.52 & 5.63 & 2.41 & 2.47 \\
\hline 13 & 1.68 & 1.35 & 1.33 & 2.18 \\
\hline 14 & 5.83 & 5.26 & 1.99 & 1.24 \\
\hline 15 & 5.49 & 4.87 & 2.37 & 1.17 \\
\hline 16 & 3.25 & 3.51 & 1.35 & 2.10 \\
\hline 17 & 2.96 & 2.69 & 1.02 & \\
\hline
\end{tabular}

The results of MRR and SR values obtained from the experiment and the modeling can be seen in Tab. 3.

\subsection{Statistical test}

Modeling equations for MRR and SR must be tested before proceeding to data processing. There are two statistical tests, which are F-test and $t$-test. Based on Eqs. 5 and 6, F values and $t$ values are obtained and shown in Tab. 4 and Tab. 5.

$$
\begin{gathered}
F=\frac{S S R / q}{S S E / n-q-1} \\
t=\frac{\widehat{\beta}_{j}}{s \sqrt{g_{j j}}} \\
s^{2}=\frac{S S E}{n-q-1}
\end{gathered}
$$

Where: SSR is the sum of squared residuals, SSE is the sum of squared errors and $s^{2}$ is the variance. Based on various previous studies, the value of the confidence level that is often used is $95 \%$, so an a value of 0.05 is obtained [18]. The values of $n$ and $q$ to determine $F$-statistics and $t$-statistics were obtained from the number of experiments and the independent variables used. The number of experiments $(n)$ is 18 and the independent variable $(q)$ is 4 .

Tab. 4 F-test Results

\begin{tabular}{|c|c|c|}
\hline Model & $F_{d r y}$ value & $F_{0.05 ; 4,13}$ \\
\hline$y_{1}$ & 82.8 & 3.18 \\
\hline$y_{2}$ & 54.9 & 3.18 \\
\hline
\end{tabular}

Tab. 5 t-test Results

\begin{tabular}{|c|c|c|c|}
\hline Variable & $t\left(y_{1}\right)$ & $t\left(y_{2}\right)$ & $t_{0.025 ; 13}$ \\
\hline$t_{1} \rightarrow x_{1}$ & 1.72 & -0.82 & 2.16 \\
\hline$t_{2} \rightarrow x_{2}$ & 5.74 & -1.38 & 2.16 \\
\hline$t_{3} \rightarrow x_{3}$ & 10.30 & 9.16 & 2.16 \\
\hline$t_{4} \rightarrow x_{4}$ & 9.77 & 2.52 & 2.16 \\
\hline
\end{tabular}


The F-test value in both equations has a greater value compared to the F-statistic. This shows that there is a difference between the variance of modeling and experiment both in the MRR value and the SR value so that the null hypothesis can be rejected. Each variance between the two populations was not obtained randomly with a confidence level of $95 \%$. These results prove that the characteristic equations obtained in MRR and SR modeling can predict the response with statistically significant.

The $t$-test value shows that in modeling $y_{1}$ (MRR), the variables that have a significant effect are $x_{2}$ (cutting speed), $x_{3}$ (feed rate), and $x_{4}$ (depth of cut), whereas two variables have a major impact on modeling $y_{2}$ (SR), namely $x_{3}$ (feed rate) and $x_{4}$ (depth of cut).

\subsection{GA implementation}

There are three important factors in the optimization process using the GA method, which are selection, crossovers, and mutations. However, the first step before determining the value and nature of each operator is to determine the solution set for the initial population form.

The set of solutions must be made into dimensionless values using Eq. 8 so that the upper and lower limits of the initial population in the GA optimization process can be seen on Tab. 6 .

$$
x_{j}^{\prime}=\frac{x_{j}-\bar{x}_{j}}{s}
$$

Tab. 6 Lower and Upper Limits of the Set of Solution

\begin{tabular}{|c|c|c|c|c|}
\hline Limit & $x_{1}$ & $x_{2}$ & $x_{3}$ & $x_{4}$ \\
\hline Lower & -0.949 & -1.48 & -1.12 & -1.48 \\
\hline Upper & 0.949 & 1.48 & 1.72 & 1.48 \\
\hline
\end{tabular}

The conditions in Tab. 6 are used for the optimization process of MRR and SR. The value and characteristic of each GA parameter can be seen on Tab. 7 . The number of variables is determined according to the independent variables used, which are the tool nose radius $\left(x_{1}\right)$, cutting speed $\left(x_{2}\right)$, feed rate $\left(x_{3}\right)$, and depth of cut $\left(x_{4}\right)$. The double vector population type is chosen because the optimization process is carried out on integers. The size of the population is determined according to the values determined by MATLAB for optimization of fewer than 5 variables, namely 50 . The use of top as an objective value scale characteristic is conducted to create a more viable new population with less diversity compared to rank characteristics. Selection with the roulette wheel character is used to increase the possibility of selecting individuals with higher fitness values so that it can speed up the optimization process. The elitism value of 2 is served to ensure the number of individuals that survived as a population in the next generation. This value is chosen because the greater the value used, the more likely it is to be trapped in the local optimal value. A small value provides a more accurate value and is close to the global optimal value [19]. High probability of crossovers with multi-point character can reduce the quality of new populations with high fitness values, resulting in poor offspring. In general, the range of probability crossover value is $0.4 \sim 1$. Uniform characters are chosen because this character is used in the integer optimization process. The smaller the probability mutation value, the faster the optimization process could obtain convergent values. The termination criteria chosen are the stall generations with a value of 70 which aims to avoid the optimization process that lasts too long.

Tab. 7 GA Parameters

\begin{tabular}{|l|c|c|}
\hline \multicolumn{1}{|c|}{ Parameters } & Description & Value \\
\hline $\begin{array}{l}\text { \# of independent var- } \\
\text { iables }\end{array}$ & - & 4 \\
\hline Population & $\begin{array}{c}\text { Double vec- } \\
\text { tor }\end{array}$ & 50 \\
\hline Scale of fitness & Top & 0.4 \\
\hline Selection & $\begin{array}{c}\text { Roulette } \\
\text { wheel }\end{array}$ & - \\
\hline Elitism & - & 2 \\
\hline Crossover & Single point & 0.7 \\
\hline Mutation & Uniform & 0.001 \\
\hline \# of iteration & $\begin{array}{c}\text { Stall genera- } \\
\text { tions }\end{array}$ & 70 \\
\hline
\end{tabular}

\section{MRR and SR}

In this study, GA was used to optimize MRR and $\mathrm{SR}$. The greater the MRR value, the more optimal it is considered. However, to adjust to the current needs of the medical industry, certain limitations are applied. In this case, the maximum surface roughness which is acceptable for bone and metal pegs is $0.6 \mu \mathrm{m}$ [20]. Furthermore, the smaller the SR value, the more optimal it is considered.

Equation limits on MRR optimization can be one of the termination conditions. If it is not fulfilled, the optimization process must be stopped. The boundary equation used in this optimization is a nonlinear inequality constraint, as follows:

$$
\begin{aligned}
& 1.88-0.0501 x_{1}-0.0794 x_{2}+0.6 x_{3}+0.162 x_{4}-0.213 x_{1} x_{2}-0.188 x_{1} x_{3}+0.156 x_{1} x_{4}+ \\
& 0.0616 x_{2} x_{3}-0.139 x_{2} x_{4}-0.116 x_{3} x_{4} \leq 0.6
\end{aligned}
$$


In optimizing SR, the limits on optimization are only the upper and lower limits of the set of solutions without any additional boundary equations. This is done to obtain the lowest possible SR value so that it can be considered optimal.

\section{Optimization results}

The optimization process is conducted with the help of MATLAB software. Eqs. 3 and 4 are used as a characteristic equation, the upper and lower limits of the solution set can be seen on Tab. 6, and the boundary equation uses Eq. 9. The results on Tab. 8 are the most optimal results obtained from 5 trials.

From the result of experiments as shown in Tab. 3 , it can be seen that $\mathrm{SR}>0.6 \mu \mathrm{m}$. The optimization results prove that using the GA method, a combination of tool nose radius, cutting speed, feed rate, and depth of cut can be obtained which are all able to produce $\mathrm{SR}<0.6 \mu \mathrm{m}$.

Tab. 8 Optimization Results of MRR and SR

\begin{tabular}{|c|c|c|c|c|}
\hline & & \multirow{2}{*}{ Unit } & \multicolumn{2}{|c|}{ Results } \\
\cline { 3 - 5 } & & MRR & SR \\
\hline Process parameters & Tool nose radius, $r_{\varepsilon}$ & $\mathrm{mm}$ & 0.4 & 0.4 \\
\hline & Cutting speed, $v_{c}$ & $\mathrm{~m}_{\mathrm{m}} \mathrm{min}^{-1}$ & 96.9 & 95 \\
\hline & Feed rate, $f$ & $\mathrm{~mm}^{-1} \mathrm{rev}^{-1}$ & 0.035 & 0.035 \\
\hline & Depth of cut, $d$ & $\mathrm{~mm}$ & 0.217 & 0.01 \\
\hline Limit & Surface roughness & $\mu \mathrm{m}$ & 0.59 & - \\
\hline Objective function & Material removal rate, MRR & $\mathrm{cm}^{3} \cdot \mathrm{min}^{-1}$ & 0.64 & - \\
\hline & Surface roughness, SR & $\mu \mathrm{m}$ & - & 0.458 \\
\hline
\end{tabular}

\subsection{Validation process and evaluation}

The validation process of the optimization results is carried out on the same machine as the experiments in the same environmental conditions. Tabs. 9 and 10 show the comparison of optimization results and validation.

\section{MRR}

Tab. 9 Comparison of MRR from Optimization and Validation

\begin{tabular}{|l|c|c|c|c|}
\hline \multicolumn{1}{|c|}{ Parameters } & Unit & Optimization & Validation & Difference \\
\hline Tool nose radius, $r_{\varepsilon}$ & $\mathrm{mm}$ & 0.4 & 0.4 & - \\
\hline Cutting speed, $v_{c}$ & $\mathrm{~m} \cdot \mathrm{min}^{-1}$ & 96.9 & 95 & $1.96 \%$ \\
\hline Feed rate, $f$ & $\mathrm{~mm}^{-\mathrm{rev}^{-1}}$ & 0.035 & 0.035 & - \\
\hline Depth of cut, $d$ & $\mathrm{~mm}$ & 0.217 & 0.216 & $0.46 \%$ \\
\hline Material removal rate, MRR & $\mathrm{cm}^{3} \cdot \mathrm{min}^{-1}$ & 0.64 & 0.61 & $4.69 \%$ \\
\hline Surface roughness, SR & $\mu \mathrm{m}$ & 0.59 & 0.56 & $5.08 \%$ \\
\hline
\end{tabular}

SR

The SR validation process is performed using the process parameters resulting from the optimization

Tab. 10 Comparison of SR from Optimization and V alidation

\begin{tabular}{|l|c|c|c|c|}
\hline \multicolumn{1}{|c|}{ Parameters } & Unit & Optimization & Validation & Difference \\
\hline Tool nose radius, $r_{\varepsilon}$ & $\mathrm{mm}$ & 0.4 & 0.4 & - \\
\hline Cutting speed, $v_{c}$ & $\mathrm{~m} \cdot \mathrm{min}^{-1}$ & 95 & 95 & - \\
\hline Feed rate, $f$ & $\mathrm{~mm} \cdot \mathrm{rev}^{-1}$ & 0.035 & 0.035 & - \\
\hline Depth of cut, $d$ & $\mathrm{~mm}$ & 0.1 & 0.1 & - \\
\hline Surface roughness, SR & $\mu \mathrm{m}$ & 0.458 & 0.49 & $6.99 \%$ \\
\hline Material removal rate, MRR & $\mathrm{cm}^{3} \cdot \mathrm{min}^{-1}$ & 0.178 & 0.17 & $4.49 \%$ \\
\hline
\end{tabular}

process. From Tab. 10, the SR from the validation process is larger $6.99 \%$ compared to the optimization results and the MRR is $4.49 \%$ smaller than the optimization results. 
The GA optimization and validation results of AISI 316L dry turning shown in Tab. 9 and Tab. 10 prove the usefulness of the model for optimal process parameters and processing performance. The optimization process of MRR and SR is close to the confirmation experiment, therefore, the optimization process using the GA method is considered to be effective.

\section{Conclusions}

The application of GA optimization for MRR and SR of AISI 316L under the dry turning process is presented in this paper. The model development considers four process parameters, namely the nose radius, cutting speed, feed rate, and depth of cut. The developed MRR and SR models were tested by F-test and $t$-test, and it was found that the $95 \%$ confidence interval was met. Cutting speed, feed rate, and depth of cut have a significant effect on MRR, while feed rate and depth of cut have a major impact on SR.

According to the modeling, optimization, and validation of the MRR and SR of AISI 316L in the dry turning process by the GA method, the following conclusions can be drawn:

- The GA method can function well for the optimization process in the dry turning process.

- The optimal MRR can be obtained with a process parameter of $0.4 \mathrm{~mm}$ for a tool nose radius; $96.9 \mathrm{~m} . \mathrm{min}^{-1}$ for cutting speed; 0.035 $\mathrm{mm} \cdot \mathrm{rev}^{-1}$ for feed rate; and $0.217 \mathrm{~mm}$ for the depth of cut, meanwhile, for the optimal SR, it is required for the following; a process parameter of $0.4 \mathrm{~mm}$ for a tool nose radius; 95 m.min ${ }^{-1}$ for cutting speed; $0.035 \mathrm{~mm} \cdot \mathrm{rev}^{-1}$ for feed rate; and $0.1 \mathrm{~mm}$ for the depth of cut.

- The MRR from the optimization process is $0.64 \mathrm{~cm}^{3} \cdot \mathrm{min}^{-1}$ which is $4.69 \%$ larger than the validation result. While the optimized SR is $0.458 \mu \mathrm{m}$ which is $6.99 \%$ smaller than the validation result.

- The optimum value of the MRR and SR can be predicted with less than a 7\% deviation from the actual value.

\section{Acknowledgement}

The authors would like to thank the Laboratory of Production, Faculty of Mechanical and Aerospace Engineering, Institut Teknologi Bandung for permission to use the facilities.

\section{References}

[1] AHILAN, C., KUMANAN, S.; SIVAKUMARAN, N., EDWIN RAJA DHAS,
J. (2013). Modeling and prediction of machining quality in CNC turning process using intelligent hybrid decision making tools. In: $A p$ plied Soft Computing, Vol. 13, No. 3, pp. 15431551. DOI:10.1016/j.asoc.2012.03.071

[2] PALANIKUMAR, K., KARUNAMOORTHY, KARTHIKEYAN, R. (2005). Assessment of factors influencing surface roughness on the machining of glass fiber-reinforced polymer composites. In: Materials and Design, Vol. 27, No. 10, pp. 862-871. DOI:10.1016/j.matdes.2005.03.011

[3] KROLCZYK, G.M., NIESLONY, P., MARUDA, R.W., WOJCIECHOWSKI, S. (2017). Dry cutting effect in turning of a duplex stainless steel as a key factor in clean production. In: Journal of Cleaner Production, Vol. 142, No. 4, pp. 3343-3354. DOI: 10.1016/j.jclepro.2016.10.136

[4] CHEN, J., WANG, Y., ZHANG, Y., YANG, S., ZHANG, X. (2020). Investigation on tool wear mechanism during dry cutting 304 stainless steel. In: Manufacturing Technology, Vol. 20, No. 1, pp. 36-44. DOI: 10.21062/mft.2020.011

[5] DAVIS, J.R. (Ed.) (2003). Handbook of Materials for Medical Devices, ASM International, Ohio.

[6] DISEGI, J.A., ESCHBACH, L. (2000). Stainless steel in bone surgery. In: Injury, Vol. 31, Suppl. 4, pp. D2-D6. DOI:10.1016/S00201383(00)80015-7

[7] ASILTÜRK, I., AKKUS, H. (2011). Determining the effect of cutting parameters on surface roughness in hard turning using the Taguchi method. In: Measurement, Vol. 44, No. 9, pp. 1697-1704.

DOI:10.1016/j.measurement.2011.07.003

[8] CHONG, E.K.P., ŻA, S.H. (2001). An Introduction to Optimization, 2nd ed. John Wiley \& Sons, New York.

[9] HARHOUT, R., GACEP, M., HADDAD, S., AGUIB, S., BLOUL, B., GUEBLI, A. (2020). Predictive modelling and optimisation of surface roughness in turning of AISI 1050 steel using polynomial regression. In: Manufacturing Technology, Vol. 20, No. 5, pp. 591602. DOI: $10.21062 / \mathrm{mft} .2020 .094$

[10] MARTOWIBOWO, S.Y., KASWADI, A. (2017). Optimization and simulation of plastic injection process using genetic algorithm and moldflow. In: Chinese Journal of Mechanical Engineering, Vol. 30, No. 2, pp. 398-406. DOI:10.1007/s10033-017-0081-9 
[11] SENTHILKUMAR, B., KANNAN, T., MADESH, R. (2017). Optimization of fluxcored arc welding process parameters by using genetic algorithm. In: The International Journal of Advanced Manufacturing Technology, Vol. 93, No. 1-4, pp. 35-41. DOI:10.1007/s00170-0157636-7

[12] KRIMPENIS, A.A., FOUNTAS, N.A., NTALIANIS, I., VAXEVANIDIS, N.M. (2014). CNC micromilling properties and optimization using genetic algorithms. In: The International Journal of Advanced Manufacturing Technology, Vol. 70, No. 1-4, pp. 157-171. DOI:10.1007/s00170-013-5248-7

[13] Mitsubishi Materials Technical Data. Retrieved May 17, 2019, from http://www.teraskonttori.fi/easydata/customers/teraskonttori/files/lastuavat/Mitsu_14_TECHNICAL_DATA.pdf.

[14] MONTGOMERY, D.C. (2008). Design and Analysis of Experiments. John Wiley \& Sons, New York.

[15] HOLLAND, J.H. (1975). Adaptation in Natural and Artificial Systems. University of Michigan Press, Ann Arbor, MI.
[16] GOLDBERG, D.E. (1989). Genetic Algorithms in Search, Optimization, and Machine Learning. Addison-Wesley, Massachusetts.

[17] MICHALEWICZ, Z. (1992). Genetic Algorithms + Data Structures $=$ Evolution Programs. SpringerVerlag Berlin Heidelberg GmbH, New York.

[18] HAZRA, A. (2017). Using the confidence interval confidently. In: Journal of Thoracic Disease, Vol. 9, No. 10, pp. 4125-4130. DOI:10.21037/jtd.2017.09.14

[19] MISHRA, A., SHUKLA, A. (2017). Analysis of the effect of elite count on the behavior of genetic algorithms: A perspective. In: Proceeding of the 2017 IEEE $7^{\text {th }}$ International Advance Computing Conference (LACC), January 5-7, pp. 835-840, Hyderabad.

[20] IMADE, S., MORI, R., UCHIO, Y., FURUYA, S. (2009). Effect of implant surface roughness on bone fixation: the differences between bone and metal pegs. In: Journal of Orthopaedic Science, Vol. 14, No. 5, pp. 652-657. DOI:10.1007/s00776-009-1369-0 